\title{
Perioperative outcome of laparoscopic left lateral liver resection is improved by using a bioabsorbable staple line reinforcement material in a porcine model
}

\author{
Esther C. J. Consten · Gregory F. Dakin · Jan-Lukas Robertus • \\ Sergio Bardaro $\cdot$ Luca Milone $\cdot$ Michel Gagner
}

Received: 14 August 2006/ Accepted: 2 November 2007/Published online: 1 February 2008

(C) The Author(s) 2008

\begin{abstract}
Hypothesis Laparoscopic liver surgery is significantly limited by the technical difficulty encountered during transection of substantial liver parenchyma, with intraoperative bleeding and bile leaks. This study tested whether the use of a bioabsorble staple line reinforcement material would improve outcome during stapled laparoscopic left lateral liver resection in a porcine model.

Study design A total of 20 female pigs underwent stapled laparoscopic left lateral liver resection. In group A $(n=10)$, the stapling devices were buttressed with a bioabsorbable staple line reinforcement material. In group B $(n=10)$, standard laparoscopic staplers were used. Operative data and perioperative complications were recorded.
\end{abstract}

This study was funded in part by a research grant from the Minimally Invasive Surgery Center of Mount Sinai School of Medicine and the Weill College of Medicine of Cornell University, which are supported by Karl Storz Endoscopy of America, Tyco Health and W.L. Gore.

E. C. J. Consten ( $\square)$

Department of Surgery, Meander Medical Center, Teaching Hospital affiliated to the University Medical Center Utrecht, Utrechtseweg 160, Amersfoort, JB 3816, The Netherlands

e-mail: ECJ.Consten@meandermc.nl

G. F. Dakin · S. Bardaro · L. Milone

Department of Surgery, Weill College of Medicine, Cornell

University, 525 East 68th Street, Box 294, New York, NY

10021, USA

\section{J.-L. Robertus}

Department of Pathology and Laboratory Medicine, University Medical Center, Groningen, The Netherlands

e-mail: j.1.robertus@path.umcg.nl

\section{Gagner}

Mount Sinai Medical Center, 4300 Alton Road, Miami Beach, FL 33140, USA
Necropsy studies and histopathological analysis were performed at 6 weeks. Data were compared between groups with the Student's $t$-test or the chi-square test.

Results Operating time was similar in the two groups $(64 \pm 11 \mathrm{~min}$ in group A versus $68 \pm 9 \mathrm{~min}$ in group B, $p=\mathrm{ns}$ ). Intraoperative blood loss was significantly higher in group B $(185 \pm 9 \mathrm{~mL}$ versus $25 \pm 5 \mathrm{~mL}, p<0.05)$. There was no mortality. There was no morbidity in the 6week follow-up period; however, two animals in group B had subphrenic bilomas (20\%) at necropsy. At necropsy, methylene blue injection via the main bile duct revealed leakage from the biliary tree in four animals in group B and none in group A $(p<0.05)$. Histopathological examination of the resection site revealed minor abnormalities in group A while animals in group B demonstrated marked fibrotic changes and damaged vascular and biliary endothelium. Conclusion Use of a bioabsorbable staple line reinforcement material reduces intraoperative bleeding and perioperative bile leaks during stapled laparoscopic left lateral liver resection in a porcine model.

Keywords Laparoscopic surgery - Liver resections . Staple line reinforcement - Complications - Bile duct leak . Hemorrhage.

The success of laparoscopic cholecystectomy has driven the application of minimally invasive techniques to other disease processes, and led to the use of laparoscopy in solid organ surgery [1-9]. Since the report of the first laparoscopic liver resection for a 6-cm focal nodular hyperplasia, laparoscopic surgery for the treatment of liver diseases has become more popular [28-30]. In 1995, excision of a segment 4 hepatic tumor was reported. The first successful 
laparoscopic left lateral hepatectomy (segments 2 and 3) in a patient with a benign adenoma was performed in 1996 [8].

Technological advances and the development of new equipment have facilitated the growing trend of laparoscopic liver resections [2]. However, laparoscopic liver surgery remains technically challenging. Compared to open surgery, the laparoscopic surgeon is limited by the lack of an effective means to divide substantial liver parenchyma. Transection of the liver can be performed laparoscopically in several different ways, however bile leakage rates of 1$16 \%$ and bleeding complication rates of $6-55 \%$ have been reported [9, 30-32].

We hypothesized that the addition of a bioabsorbable membrane to reinforce standard laparoscopic stapling devices would reduce the bleeding and biliary complications of stapled laparoscopic liver resections. We tested this hypothesis in a prospective survival study of 20 pigs undergoing laparoscopic left lateral liver resections.

\section{Methods}

Study design

A total of 20 female pigs each weighing approximately 40 $\mathrm{kg}$ were used for the study. All animals were maintained in accordance with the recommendations of the institutional animal care and use committee at the Mount Sinai School of Medicine. Animals were randomly assigned at the time of surgery to either group A $(n=10)$ in which the stapling devices used for laparoscopic left lateral segmentectomy were reinforced with a bioabsorbable membrane or group $\mathrm{B}(n=10)$, in which standard stapling devices were used. Animals were followed prospectively for a 6-week period after which they were sacrificed.

\section{Surgery}

All animals were premedicated with ketamine $(22 \mathrm{mg} / \mathrm{kg})$ and atropine $(0.04 \mathrm{mg} / \mathrm{kg})$ and anesthetized with thiopentothal $(15 \mathrm{mg} / \mathrm{kg})$ prior to intubation. Animals were then mechanically ventilated with an initial tidal volume of 10 $\mathrm{ml} / \mathrm{kg}$ and a respiratory rate of 15 breaths per minute. The tidal volume was adjusted to maintain arterial $P_{\mathrm{a}} \mathrm{CO}_{2}$ of $35-40 \mathrm{mmHg}$ during the experiment. Anesthesia was maintained with inhaled isofluorane (1.5\%).

The pig was placed in a supine position. A standard open technique was used to gain access to the abdomen and a total of five trocars (Karl Storz Endoscopy America, Culver City, CA, USA) were used for the procedure (Fig. 1).

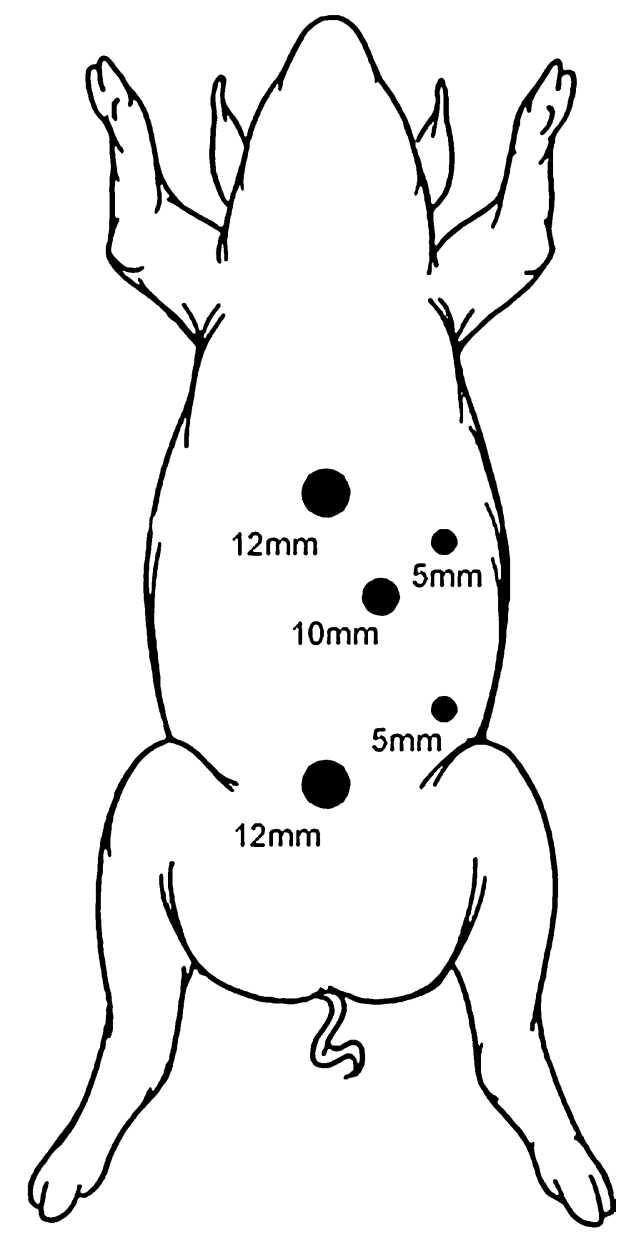

Fig. 1 Schematic illustration of trocars placement in the porcine model

Pneumoperitoneum was established to a pressure of 15 $\mathrm{mmHg}$. After inspection of the abdominal cavity with a 10$\mathrm{mm} 30^{\circ}$ laparoscope, the remaining trocars were placed under direct vision. Two $10-\mathrm{mm}$ trocars were used in the left and right upper quadrants. One 12-mm trocar was positioned in the left anterior axillary line for liver retraction. The liver capsule and parenchyma were inspected superiorly and inferiorly and the line of transection was visualized between the liver hilum, along the surface of the entire left liver lobes towards the diaphragm. Subsequently, the left lateral segmentectomy was demarcated (segments 2 and 3 of the liver) within $1 \mathrm{~cm}$ along the falciform ligament. If necessary, the diaphragmatic and minor omental attachments to the liver were divided to mobilize the left lobe. Once mobilized, attention was turned to transection of the liver parenchyma. This was accomplished with sequential firings of a $3.5-\mathrm{mm}$ endo GIA stapler (US Surgical, Norwalk, CT). In group A, the stapler cartridges were buttressed with a bioabsorble reinforcement material (Seamguard $\AA$, W.L. Gore, Flagstaff, 


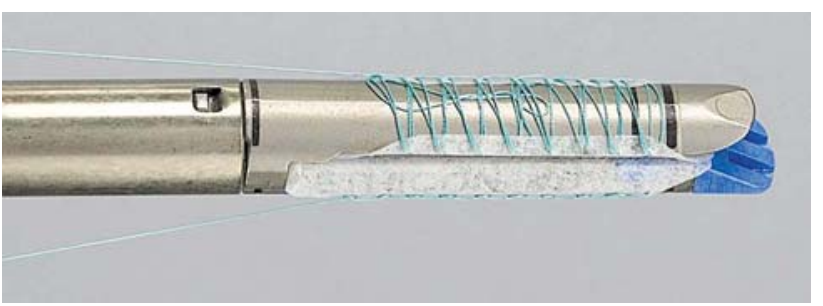

Fig. 2 An absorbable polymer membrane (Bioabsorbable Seamguard, W.L. Gore, Flagstaff, Arizona, USA) is constructed as a buttress mat integrated in the stapler systems

Arizona) (Fig. 2). In group B the standard stapler cartridges were used. As the liver parenchyma was divided, no attempt was made to isolate the major feeding vessels (major branches of the left hepatic artery and vein) to segments 2 and 3; rather, they were divided en masse with the liver parenchyma. Upon completion of the transection, hemostasis was achieved with the ultrasonic scalpel (Ethicon Endo-Surgery, Cincinatti, Ohio, USA), which works by means of a vibrating blade or scissors and can effectively seal small vessels and bile ducts, and/or electrocautery. The resected specimen was placed into an endobag and retrieved through the umbilical trocar site that was extended approximately $3.5-5.0 \mathrm{~cm}$ to accommodate the specimen. The abdomen was irrigated and inspected prior to closure of the trocar sites. No intra-abdominal drains were used.

\section{Data collection}

Operative data recorded at the time of surgery included operative time, specimen size, and blood loss as estimated by amount of fluid collected in a suction container minus irrigation fluid used. Animals were prospectively followed with regard to clinical outcome for 6 weeks. Clinical status (temperature, blood pressure $=\mathrm{BP}$, heart rate $=\mathrm{HR}$ ) was examined routinely on a daily basis unless clinical condition mandated additional assessment. Routine blood tests (bilirubin, ALT, AST, alkaline phosphatase, GGT, and complete blood count) were obtained 2 days and 6 weeks postoperatively.

Animals were sacrificed at 6 weeks and examined for intra-abdominal abnormalities such as abscess or bile leaks. Standard methylene blue was injected into the biliary tree to examine for active biliary leaks. A standardized pressure-controlled injector using a green sized syringe injected 5-10 $\mathrm{ml}$ methylene blue into the ligated common bile duct. Subsequently, the cut edge of the liver was examined both macroscopically and microscopically for evidence of biliary leak. The cut edge of the liver was then sent for histopathological analysis.
Statistical analysis

To obtain a $50 \%$ reduction rate in postoperative outcome after laparoscopic liver resection an $80 \%$ power analysis showed a series of 20 consecutive animals to be operated. Moreover, a 95\% confidence interval was obtained to achieve statistical significance. Data were compared between groups with Student's $t$-test and chi-square tests.

\section{Results}

All animals tolerated the procedure well and were healthy during the entire follow up. Clinical status (temperature, blood pressure, heart rate) examined routinely on a daily basis were not different. All animals resumed normal diet within 1 day and had their first bowel movement within 23 days. Routine blood tests (bilirubin, ALT, AST, alkaline phosphatase, GGT, white blood cell, hemoglobin, hematocrit) obtained 2 days and 6 weeks postoperatively showed no abnormalities in either group.

Mean operative time was not different between groups (group A $64 \pm 11 \mathrm{~min}$ versus group B $68 \pm 9 \mathrm{~min}$, $p=\mathrm{ns}$ ). Intraoperative blood loss was significantly higher in group B $(25 \pm 5 \mathrm{~mL}$ versus $185 \pm 9 \mathrm{~mL}, p<0.05)$ (Fig. 3). An average of six 60-mm stapler cartridge firings per animal were used in each group to transect the left lateral liver lobe $(p=\mathrm{ns})$. Resected specimen size was similar in both groups (average size $10 \times 8 \times 4 \mathrm{~cm}$; average weight $0.41 \mathrm{~kg}$ ). There was no morbidity or mortality in either group. However, two animals in group B were found to have bile collections in the previous operating field at the time of necropsy. When the livers were subjected to methylene blue injection via the common bile duct (CBD), two additional animals in group $\mathrm{B}$ were found to have evidence of biliary leak (a total of four of ten animals in group $\mathrm{B}$ versus zero of ten in group A, $p<0.05)$.

Histopathological examination of the cut surface of the liver in group A revealed no evidence of the staple line

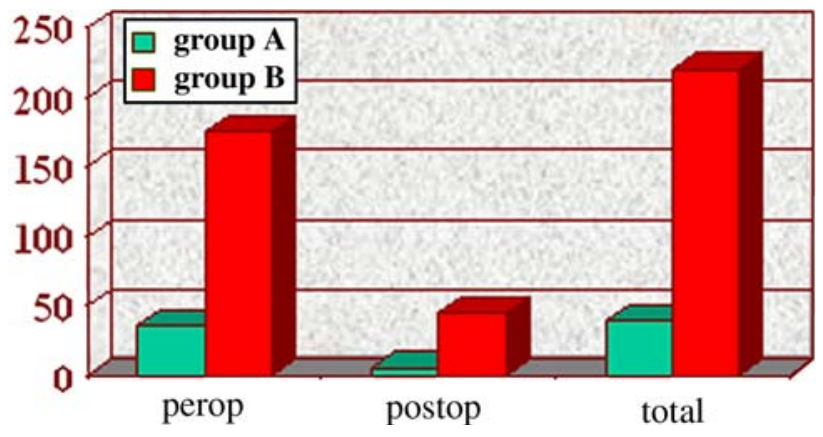

Fig. 3 Intraoperative blood loss in groups A and B 
reinforcement material, indicating that it had been totally reabsorbed. There was no bile duct damage seen and only mild mononuclear inflammation was seen in the portal areas. Subcapsular sinusoid dilation and congestion was seen with sharp demarcation between areas of dilation and absence of dilation in a pattern suggestive of fixation artifact although ischemic or anoxic damage cannot be ruled out. In group B marked fibrotic changes and damaged vascular and biliary endothelium were seen (Fig. 4 and 5).

\section{Discussion}

While new technology is rapidly expanding the realm of laparoscopic surgery to include major hepatic resections, the majority of laparoscopic hepatic operations currently performed are for diagnostic purposes [3-5]. One of the major limitations to laparoscopic liver resections is the difficulty encountered in division of substantial liver parenchyma. Commonly employed devices for standard
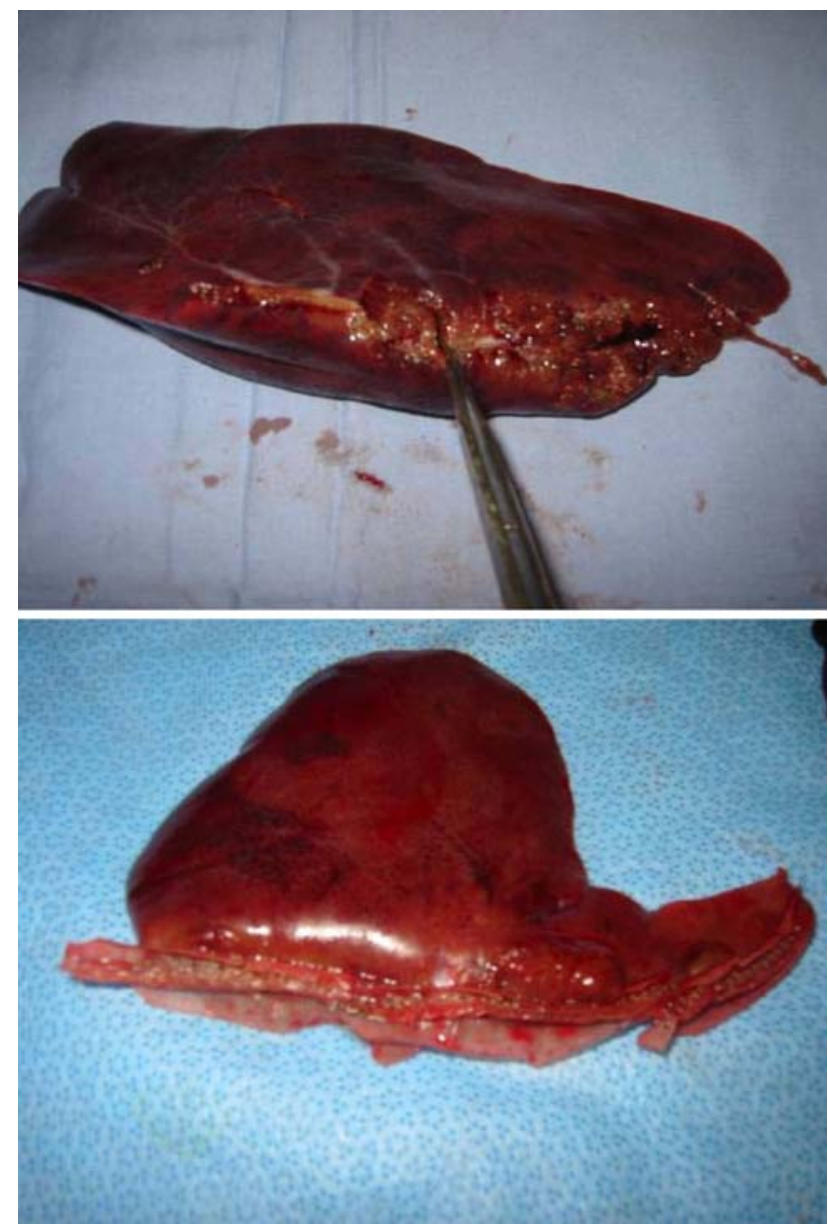

Fig. 4 Macroscopic illustration of bile duct damage at the liver's transection site of group B in which conventional stapling technique was performed
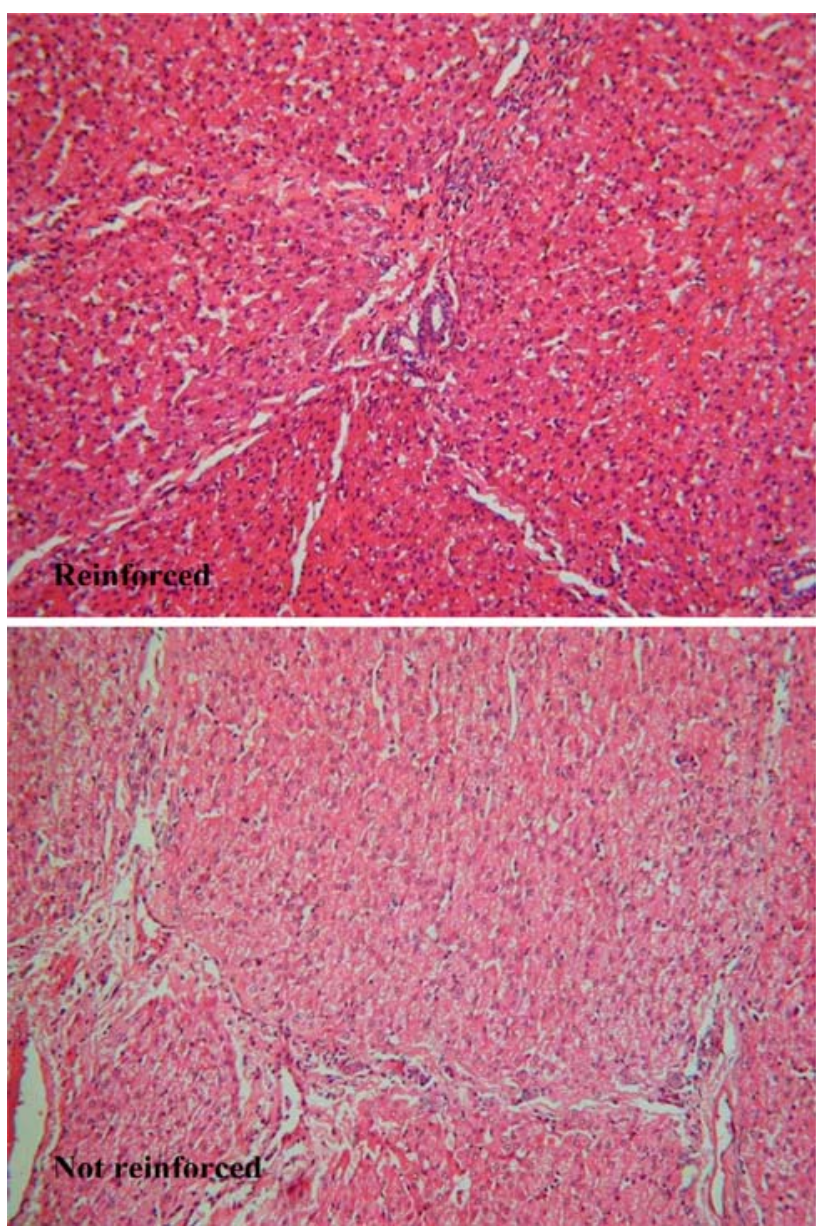

Fig. 5 Microscopic examination $(20 \times)$ of resection line of group A (above) and group B (below)

open liver resections including the Cavitron ultrasonic surgical aspirator (CUSA) (Valleylab, Boulder, CO), and the Argon Beam coagulator (Valleylab, Boulder, CO) are available for use in laparoscopy [34-36].

Transecting the liver can be performed in laparoscopically several ways (varying from gasless procedures to hand-assisted or strict laparoscopic liver resections), each technique with its own risk of bleeding and bile leaks. In the past, the percentage of these complications has not changed considerably, remaining between $10 \%$ and $50 \%[9,31]$. Commonly used laparoscopic devices such as the ultrasonic scalpel or the Ligasure (Valleylab, Boulder, CO) are limited in their ability to divide liver parenchyma because of the small size of the active heating area.

The addition of various buttressing materials to stapling devices has been tried as a means to improve results and reduce complications rates in both pulmonary and gastrointestinal surgery [17-23]. We hypothesized that the addition of a buttressing material to standard laparoscopic stapling devices wouldprovide a novel technique for liver 
transection. One buttressing material (Seamguard $®$, W.L. Gore, Flagstaff, Arizona) is a porous fibrous structure composed solely of synthetic bioabsorbable poly (glycolide:trimethylene carbonate) copolymer. Degraded via a combination of hydrolytic and enzymatic pathways, the copolymer has been found to be both biocompatible and nonantigenic, with a history of use as bioabsorbable sutures, membranes, and other implantable devices. When used for staple line reinforcement, it can be expected to retain mechanical strength for 4-5 weeks and be completely absorbed by the end of 6 months [11]. The fact that this material is completely bioabsorbable should reduce concerns over possible long-term complications such as migration, erosion, calcification, and infection. In addition, this synthetic copolymer does not carry the risk of animal source contamination. The histopathological examination of the resection line of both groups showed fibrotic changes in group B in contrast to group A. This may be caused by excess mechanical stress which was avoided in group A due to addition of a staple line reinforcement.

Our results show that transaction using conventional stapling devices is inadequate but that the addition of a bioabsorbable staple line reinforcement material to standard laparoscopic stapling devices can reduce intraoperative blood loss during transection of liver parenchyma. In addition, there was a reduction in postoperative bile leaks, although in this study these leaks were not clinically significant. Bioabsorbable reinforcement improves on complications and is a viable addition to laparoscopic liver resection.

Open Access This article is distributed under the terms of the Creative Commons Attribution Noncommercial License which permits any noncommercial use, distribution, and reproduction in any medium, provided the original author(s) and source are credited.

\section{References}

1. Montorsi M, Santambrogio R, Bianchi P, et al. (2001) Laparoscopy with laparoscopic ultrasound for pretreatment staging of hepatocellular carcinoma: a prospective study. J Gastrointest Surg 5(3):312-315

2. Descottes B, Lachachi F, Durand-Fontanier S, Sodji M, Pech de Laclause B, Valleix D (2000) [Laparoscopic treatment of solid and cystic tumors of the liver. Study of 33 cases]. Ann Chir 125(10):941-947. French

3. Kamel IR, Choti MA, Horton KM, Braga HJ, Birnbaum BA, Fishman EK, Thompson RE, Bluemke DA (2003) Surgically staged focal liver lesions: accuracy and reproducibility of dualphase helical CT for detection and characterization. Radiology 227(3):752-757

4. Descottes B, Glineur D, Lachachi F, et al. (2003) Laparoscopic liver resection of benign liver tumors. Surg Endosc 17(1):23-30

5. Cherqui D, Husson E, Hammoud R, et al. (2000) Laparoscopic liver resections: a feasibility study in 30 patients. Ann Surg 232(6):753-762
6. Mouiel J, Katkhouda N, Gugenheim J, Fabiani P (2000) Possibilities of laparoscopic liver resection. J Hepatobiliary Pancreat Surg 7(1): $1-8$

7. Gramatica L Jr, Herrera MF, Mercado-Luna A, Sierra M, Verasay G, Brunner N (2002) Videolaparoscopic resection of insulinomas: experience in two institutions. World J Surg 26(10):1297-1300

8. Ferzli G, David A, Kiel T (1995) Laparoscopic resection of a large hepatic tumor. Surg Endosc 9:733-735

9. Gigot JF, Glineur D, Azagra JS, Goergen M, Ceuterick M (2002) Laparoscopic liver resection for malignant liver tumors preliminary results of a multicenter European study. Ann Surg 236(1):90-97

10. Brolin RE (1985) Laboratory evaluation of four techniques of stapled gastroplasty. Surgery 97(1):66-71

11. Katz AR, Mukherjee DP, Kaganov AL, Gordon S (1985) A new synthetic monofilament absorbable suture made from polytrimethylene carbonate. Surg Gynecol Obstet 161(3):213-222

12. Bourne RB, Bitar H, Andreae PR, Martin LM, Finlay JB, Marquis F (1988) In-vivo comparison of four absorbable sutures: vicryl, dexon plus, maxon and pds. Can J Surg 31:43-45

13. Sanz LE, Patterson JA, Kamath R, Willett G, Ahmed SW, Butterfield AB (1988) Comparison of Maxon suture with Vicryl, chromic catgut, and PDS sutures in fascial closure in rats. Obstet Gynecol 71(3 Pt 1):418-422

14. Metz SA, Chegini N, Masterson BJ (1990) In vivo and in vitro degradation of monofilament absorbable sutures, PDS and Maxon. Biomaterials 11(1):41-45

15. Kangas J, Paasimaa S, Makela P, et al. (2001) Comparison of strength properties of poly-L/D-lactide (PLDLA) 96/4 and polyglyconate (Maxon) sutures: in vitro, in the subcutis, and in the achilles tendon of rabbits. J Biomed Mater Res 58(1):121-126

16. Kawamura M, Kase K, Sawafuji M, Watanabe M, Horinouchi H, Kobayashi K (2001) Staple-line reinforcement with a new type of polyglycolic acid felt. Surg Laparosc Endosc Percutan Tech 11(1):43-6

17. Miller JI, Landreneau RJ, Wright CE, Santucci TS, Sammons BH (2001) A comparative study of buttressed versus nonbuttressed staple line in pulmonary resections. Ann Thorac Surg 71(1):319322

18. Murray KD, Ho CH, Hsia JY, Little AG (2002) The influence of pulmonary staple line reinforcement on air leaks. Chest 122(6):2146-2149

19. Itoh E, Matsuda S, Yamauchi K, Oka T, Iwata H, Yamaoka Y, Ikada Y (2000) Synthetic absorbable film for prevention of air leaks after stapled pulmonary resection. J Biomed Mater Res 53(6):640-645

20. Fischel RJ, McKenna RJ Jr (1998) Bovine pericardium versus bovine collagen to buttress staples for lung reduction operations. Ann Thorac Surg 65(1):217-219

21. Hazelrigg SR, Boley TM, Naunheim KS, Magee MJ, Lawyer C, Henkle JQ, Keller CN (1997) Effect of bovine pericardial strips on air leak after stapled pulmonary resection. Ann Thorac Surg 63(6):1573-1575

22. Shikora SA, Kim JJ, Tarnoff ME (2003) Reinforcing gastric staple-lines with bovine pericardial strips may decrease the likelihood of gastric leak after laparoscopic Roux-en-Y gastric bypass. Obes Surg 13(1):37-44

23. Chae FH, McIntyre RC, Stiegmann GV (2001) Anastomotic staple-line reinforcement enhances the safety of laparoscopic Roux-en-Y gastric bypass for morbid obesity. Obes Surg 11

24. Shamji MF, Maziak DE, Shamji FM, Matzinger FR, Perkins DG (2002) Surgical staple metalloptysis after apical bullectomy: a reaction to bovine pericardium? Ann Thorac Surg 74(1):258-261

25. Provencher S, Deslauriers J (2003) Late complication of bovine pericardium patches used for lung volume reduction surgery. Eur J Cardiothor Surg 23(6):1059-1061 
26. Ahmed S, Marzouk K, Bhuiya T, Iqbal M, Rossol L (2001) Asymptomatic expectoration of surgical staples complicating lung volume reduction surgery. Chest 119:307-308

27. Oey I, Waller D (2001) Metalloptysis: a late complication of lung volume reduction surgery. Ann Thorac Surg 71(1):16941695

28. Gagner M, Rheault M, Dubuc J (1992) Laparoscopic partial hepatectomy for liver tumor. Surg Endosc 6:99

29. Yi-Tao Ding, Xi-Tai Sun, Qing-Xiang Xu (2002) Non-bleeding technique in resection of hepatoma: report of 49 cases. Hepatobiliary Pancreat Dis Int 1(1):52-6

30. Azagra JS, Goergen M, Gilbart E, Jacobs D (1996) Laparoscopic anatomical (hepatic) left lateral segmentectomy-technical aspects. Surg Endosc 10(7):758-761

31. Dagher I., Proske JM, Carloni A, Richa H, Tranchart H, Franco D (2007) Laparoscopic liver resection: results for 70 patients. Surg Endosc 21(4):619-624
32. Simillis C, Constantinides VA, Tekkis PP, Darzi A, Lovegrove R, Jiao L, Antoniou A (2007) Laparoscopic versus open hepatic resections for benign and malignant neoplasms-a meta-analysis. Surgery 141(2):203-211

33. Vibert E, Perniceni T, Levard H, Denet C, Shahri NK, Gayet B (2006) Laparoscopic liver resection. Br J Surg 93(1):67-72

34. Lesurtel M, Cherqui D, Laurent A, Tayar C, Fagniez PL (2003) Laparoscopic versus open left lateral hepatic lobectomy: a casecontrol study. J Am Coll Surg 196(2):236-242

35. Cherqui D, Husson E, Hammoud R, Malassagne B, Stephan F, Bensaid S, Rotman N, Fagniez PL (2000) Laparoscopic liver resections: a feasibility study in 30 patients. Ann Surg 232(6):753-762

36. Pinto PA, Montgomery RA, Ryan B, Roberts W, Hsu T, Kavoussi P, Klein AS, Kavoussi LR, Molmenti EP (2003) Laparoscopic procurement model for living donor liver transplantation. Clin Transplant 17(Suppl 9):39-43 